\title{
The Outcome of Withholding Pharmacologic Treatment in Children with Acute ITP
}

Jalil I Alezzi (FICMS) ${ }^{1}$, Maghrib S. AlKhateeb (DCH) ${ }^{2}$ and Emad Wisam Hassan $(\mathrm{FICMS})^{3}$

\begin{abstract}
Background: ITP is a nonthreatening disorder disturbing children at any age but mostly below 5 years.

Objective: To evaluate the outcome of children with acute ITP who were not specified with any pharmacologic action and linked with those who were treated.

Patients and Methods: A prospective case- control study was done between Jan.2002 to May 2016 at Mukalla children and Maternity Hospital and University Hospital for Children and Mother Health in Mukalla/ Hadhramout /Yemen, where 20 children with acute ITP. the control group was 18 children given the conventional therapy. The identification and grouping of ITP were made according to the 2009 International Working Group criteria.

Results: In group A there were 11( 55\%) boys and 9(45\%) girls, while control group B there were 18 children $10(55.5 \%)$ boys and $8(44.5 \%)$ girls. the ages were from 2 to 12 years. The mean age is 4.7 years with the median age at identification was $4 \mathrm{r}$ years. There was no statistical significant difference between both groups regarding outcome.

Conclusion: The recovery percentage has some relation with age at appearance and preliminary platelet count where younger children and those with platelet amount of $<20000$ $/ \mu \mathrm{L}$ have better recovery percentage. There was no statistical significant difference between both groups regarding outcome.
\end{abstract}

Keywords: ITP, Withholding, Outcome

Corresponding Author: jalilkadim@gmail.com

Received: $24^{\text {th }}$ February 2019

Accepted: $13^{\text {th }}$ May 2019

\footnotetext{
${ }^{1}$ College of Medicine - University of Diyala -Diyala-Iraq.

${ }^{2,3}$ AlBatool Teaching Hospital -Diyala-Iraq.
}

\section{Introduction}

Immune thrombocytopenic purpura is an insulated low platelets count $<100,000 / \mu \mathrm{L}$ with ordinary white blood cell count and hemoglobin level ) [1-3]. ITP is a nonthreatening disorder for greatest affected children [4-7]. Brain 1 hemorrhage is the most grave sequela of ITP; luckily, it occurs in $0.1 \%-<1 \%$ of cases. [8-11]. There is no proof that treatment avert severe hemorrhage in children with ITP [11]. ITP can disturb any age, nonetheless there is a greatest occurrence among 2-5 years, and the boy/girl 
proportion was highest in infants and declined with age [12-14]. Children under 10 years of age are more probable to recover than older children $[1,13,15,16]$. Treatment documents are restricted in affected children and suggestions for therapy are unstandardized. Up to the present time, there is no perfect study which praises reserve treatment in newly identified ITP irrespective of platelet count. Suitable initial management may be either "vigilant waiting" or drugs therapy [2,17-19]. Society of Hematology endorses that kids who have no hemorrhage or trivial bleed like bruising and petechiae be allocated with follow up only irrespective of platelets number [19].

Around $20 \%$ of patients still have chronic ITP whether given treatment or not, Chronic ITP is defined as low platelet count for additional one year from appearance [1,11,20-22]. Chronicity is amplified with medications particularly methylprednisolone and immunoglobulin [23] Life-frightening bleed did not happen in the first 6 months after identification [24].

What is known? Information are restricted in childhood ITP and clues for therapy were not unvarying. Up to this time there is no definite article mentions reserve therapy in freshly identified ITP.

What is new? There is no necessity to hurry to start pharmacologic treatment regardless of initial platelet count at least in mild and moderate ITP.

The aims of the study to evaluate the end results of patients with freshly diagnosed ITP who were not specified with any medications then match them with individuals who were treated traditionally, and to see the affected age and gender as well as the association of preliminary platelet number at appearance with the end results of the illness in both groups.

\section{Patients and Methods}

Sample size: Thirty-eight Yemeni children with acute ITP, were involved in a casecontrol study, between Jan.2002 to May 2016. The children were divided into two groups, group A included 20 children (11 males and 9 females) and group B comprised 18 children (10 males and 8 females), as a control group. Group A was not prescribed any mode of pharmacologic treatment, while group B were treated with the present treatment of acute ITP (eg. steroids, immune globulin, anti-D, etc.). All children were followed up during the course of the illness to assess the outcome of the disease. The ages included $2-12$ years. The distinct age sets were 2- $<5$ years, 5- $<8$ years, and 8-12 ages. Site of the study: Mukalla children and Maternity Hospital and University Hospital for Children and Mother Health in Mukalla/ Hadhramout /Yemen.

The identification of ITP: Analysis and ordering of ITP were completed in accordance with International Working Group criteria [2]. The ensuing investigations were done: Complete blood count, and platelet number less than $100,000 / \mu \mathrm{L}$ was included. Analysis of the blood film was done by an experienced hematologist who was not propose other causes for the low platelet number. Bone marrow examination 
was done to all patients, and read by expert hematologist The findings go with the identification of ITP [24]. Further tests included ANA, feces for H. Pylori Antigen, HBsAg, HCV and HIV antibodies were performed when needed and totally they were were negative. Antibodies against platelets test didnot done as it is not crucial for diagnosis [17, 22, 23]. Fundoscopy was done when indicated and luckily was normal. The only management given for the patients in group A was activity restriction, averting of harmful medicines, regular watching of platelet count, and checking for clinical hemorrhage, while patients in group B were given the traditional treatment (steroids, immunoglobulins and others).

Anew identified ITP is an ITP identification in less than three months [1]. Chronic ITP is delineated if the illness persisted above 12 months [1, 11, 20-22].

\section{Moral approval}

This work was led in accordance to ethics of the Declaration of Helsinki, and permitted by the Ethical Research Committee at Hadhramout University /College of Medicine. The none treatment choice was meticulously elucidated to those who are responsible the children involved in the study and their consent was gained.

\section{Statistical analysis}

The information were handled and scrutinized by laptop and was evaluated by percentage and ratio. Chi square test was achieved using the SPSS program version 20 for Windows (IBM Corp, Armonk, NY, USA). A $\mathrm{P}$ value $<0.05$ was taken noteworthy, and the confidence interval was agreed at $95 \%$. Disclosure. The authors have no encounter of interest, and the study was not covered or financed by any medication corporation.

\section{Results}

Table (1) displays the dissemination of age clusters, sex and preliminary platelet number at the period of appearance in all children, where in-group A male constituted 55\% and female $45 \%$ and those below 5 years of age constituted $65 \%$. In group B there were 18 patients with 10 males and 8 females and those below 5 years of age constituted $55.5 \%$. In both groups the preliminary platelet counts ranged from 4000 20000/ $\mu$ L. Table (2) shows association among preliminary platelet number and the end results of the illness throughout the monitoring period of all patients with acute ITP where, children with initial platelet count between. 4000-10000/ $\mu \mathrm{L}$ has the uppermost remission rate in both groups and those with $\geq 20000$ has the lowest cutback rate. Table 3: shows association between age clusters at appearance and end results of all patients with acute ITP where those below 5 years of age has the uppermost remission rate and those between age of $8-12$ years has the lowest remission rate in both groups. 
Table (1): Dissemination of age groups, sex \& preliminary platelet counts at period of presentation of all patients with acute ITP.

\begin{tabular}{|c|c|c|c|c|c|c|}
\hline \multirow{3}{*}{$\begin{array}{l}\text { Age (in years) } \\
\text { Group A }\end{array}$} & \multicolumn{5}{|c|}{ Gender } & \multirow{3}{*}{$\frac{\text { Initial platelet count } / \mu \mathrm{L}}{4000-20000}$} \\
\hline & \multirow{2}{*}{\begin{tabular}{r|} 
Male \\
11
\end{tabular}} & \multicolumn{2}{|c|}{ Female } & \multirow[b]{2}{*}{$45 \%$} & \multirow[b]{2}{*}{$45 \%$} & \\
\hline & & $55 \%$ & 9 & & & \\
\hline $2-<5$ & 8 & $40 \%$ & & 5 & $25 \%$ & $4000-\leq 10000$ \\
\hline $5-<8$ & 2 & $10 \%$ & & 2 & $10 \%$ & $5000-20000$ \\
\hline $8-12$ & 1 & $5 \%$ & & 2 & $10 \%$ & $10000-20000$ \\
\hline Group B & 10 & $55.5 \%$ & 8 & $44.5 \%$ & "44.4\% & 4000-20000 \\
\hline $2-<5$ & 6 & $60 \%$ & & 4 & $50 \%$ & $4000-\leq 10000$ \\
\hline $5-<8$ & 2 & $20 \%$ & & 3 & $7.5 \%$ & $5000-20000$ \\
\hline $8-12$ & 2 & $20 \%$ & & 1 & $2.5 \%$ & $10000-20000$ \\
\hline
\end{tabular}

Table (2): Association among preliminary platelet number and outcome of illness during monitoring period of all patients with acute ITP.

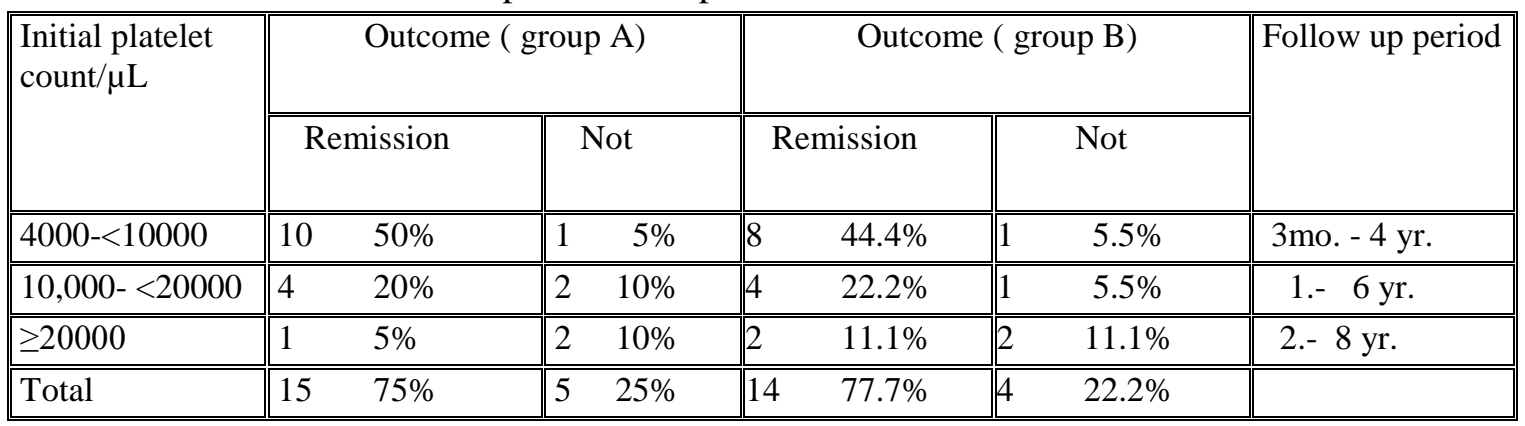

Table (3): Association among age clusters at appearance \& ending of all patients with acute ITP in the study.

\begin{tabular}{|c|c|c|c|c|c|c|c|}
\hline \multirow[t]{2}{*}{ Age (in years) } & \multicolumn{4}{|c|}{ Outcome (group B) } & \multirow{2}{*}{\multicolumn{2}{|c|}{$\frac{\text { Outcome (group A) }}{\text { Remission }}$}} & \multirow[b]{2}{*}{ Not } \\
\hline & & Remission & & Not & & & \\
\hline $2-<5$ & 8 & $44.4 \%$ & 0 & & 9 & (45\%) & 0 \\
\hline $5-<8$ & 4 & $22.2 \%$ & 2 & $11.1 \%$ & 4 & $(20 \%)$ & $(10 \%)$ \\
\hline $8-12$ & 2 & $11.1 \%$ & 2 & $11.1 \%$ & 2 & $(10 \%)$ & (15\%) \\
\hline Total & 114 & $77.7 \%$ & 4 & $22.2 \%$ & 15 & $(75 \%)$ & $(25 \%)$ \\
\hline
\end{tabular}

\section{Discussion}

ITP is a nonthreatening disorder disturbing children of diverse age clusters, the bulk of affected patients in this work were under five years in both groups. that is in covenant with former works [12-15], undoubtedly these age clusters are more possible to have viral infections and vaccination. There is a slight dominance of males, specifically in infancy. In group A, the boy/girl ratio was 1.6:1 while in group $\mathrm{B}$ it was $1.5: 1$ in the age groups 
below five, and nearly equal after this age possibly being a male is a risk factor, which is comparable to that seen in former researchers [12-14].

Platelet numbers in kids are commonly rather lower than in grownups with ITP. In both groups of study the preliminary platelet number of $\leq 10000 / \mu \mathrm{L}$ was seen in $65 \%$ and $55.5 \%$ of patients correspondingly, that is covenant with what was found by Kühne and Rosthøj [13.24]. The bulk of patients improved from ITP (i.e., platelet number rises to $>150,000 / \mu \mathrm{L}$ ) around 3-6 months of appearance, with or deprived of medications $[5-8,14,17,24]$. In this article the patients in group A was not specified with any mode of remedy throughout first 6 months of the disease and monitored carefully throughout this time for somewhat major hemorrhage, luckily no dangerous hemorrhage ensued, and nobody died. nobody has brain or gastrointestinal hemorrhage, but they have minor skin and mucus membrane hemorrhages with nosebleed which was dealt with conventionally and assurance of the patients.

Preliminary little platelet counts $(\leq 10000 / \mu \mathrm{L})$ is not scary to the physicians and family as it is linked to great cure proportion. It was seen in earlier studies that preliminary little platelet counts $(\leq 20000$ / $\mu \mathrm{L}$ ) and patients under 10 years old at appearance have the upper cure percentage [8,13,26-30].

In this study the recovery rate was $70 \%$ and $66.6 \%$ in both groups ( $\mathrm{A}$ and. $\mathrm{B}$ ) individually of those with platelet number $<20000 / \mu \mathrm{L}$, and the patients in both groups $\leq 8$ years old had a greater recovery rate in contrast to $\begin{array}{lllll}\text { above } 8 \text { years old } \quad(65 \% & 66.6 \%)\end{array}$ correspondingly. Concerning recovery rate, there is no significant statistical difference between both groups regarding ages, genders, preliminary platelet count and medications, No significant statistical difference between both groups of the study, so there is no need to start drug therapy depending on the preliminary platelet count or minor pinpoint bleeds and nosebleeds.

\section{Conclusions}

The greatest age cluster affected was $\leq 5$ in both groups with a boy/ girl proportion was 1.6: 1. and 1.5:1 in both groups respectively. Group A was not specified for any mode of pharmacologic medication in the first 6 months of the disease. The young patients and individuals with platelet number of $<20000 / \mu \mathrm{L}$ have superior remission percentage. The cure proportion in study group A was $75 \%$ while $25 \%$ (mostly females) developed prolonged sequence of the illness. while in control group it was $77.7 \% \quad 22.2 \%$ conceded into chronic sequence.

\section{Recommendations}

1-Reserve medications in children with ITP at least in insignificant to moderate conditions .and attentive coming up is the finest select for ITP treatmentt regardless of preliminary platelet number.

2-Additional scientific works are recommended to approve the outcomes of this work and to lay a regularization of ITP management in kids. 


\section{References}

[1]Rodeghiero F, Stasi R, Gernsheimer T, et al. Standardization of terminology, definitions and outcome criteria in immune thrombocytopenic purpura of adults and children: report from an international working group. Blood ; 113-2386. 2009.

[2]Provan D, Stasi R, Newland AC, et al. International consensus report on the investigation and management of primary immune thrombocytopenia. Blood ; 115:168. 2010.

[3]D'Orazio JA, Neely J, Farhoudi N. ITP in children: pathophysiology and current treatment approaches. J Pediatr Hematol Oncol ; 35:1. 2013.

[4]Tarantino MD, Young G, Bertolone SJ, et al., Single dose of anti-D immune globulin at $75 \mathrm{microg} / \mathrm{kg}$ is as effective as intravenous immune globulin at rapidly raising the platelet count in newly diagnosed immune thrombocytopenic purpura in children. J Pediatr; 148:489. 2006.

[5]Donato H, Picón A, Martinez M, et al Demographic data, natural history, and prognostic factors of idiopathic thrombocytopenic purpura in children:. J Pediatr Blood Cancer; 52(4):491. 2009.

[6]Jung JY, O AR, Kim JK, Park M Clinical course and prognostic factors of childhood immune thrombocytopenia: single center experience of 10 years; Korean J Pediatr. Aug; 59(8):335-40. 2016.

[7] Cuker A, Cines DB, Neunert CE Controversies in the treatment of immune thrombocytopenia ; Curr Opin Hematol. Sep; 23(5):479-85 2016
[8]Revel-Vilk S, Yacobovich J, Frank S, et al. Age and duration of bleeding symptoms at diagnosis best predict resolution of childhood immune thrombocytopenia at 3, 6, and 12 months. J Pediatr; 163:1335. 2013.

[9]Sadowitz D, Souid AK, Terndrup TE.; Idiopathic thrombocytopenic purpura in children: recognition and management. Pediatr Emerg Care; 12:222. 1996.

[10]Neunert C, Noroozi N, Norman G, et al Severe bleeding events in adults and children with primary immune thrombocytopenia: a systematic review; J Thromb Haemost.; 13(3):457. 2015.

[11]Scott J Paul Platelet and Blood Vessel Disorders; In Nelson textbook of Pediatrics 20th ed. ; Ch.484; PP.2402-4. 2016.

[12]Stirnemann J, Kaddouri N, Khellaf M, et al. Vincristine efficacy and safety in treating immune thrombocytopenia: a retrospective study of 35 patients. Eur J Haematol 96:269. 2016.

[13]Kühne T, Buchanan GR, Zimmerman S, et al A prospective comparative study of 2540 infants and children with newly diagnosed idiopathic thrombocytopenic purpura (ITP) from the Intercontinental Childhood ITP Study Group. J Pediatr; 143:605. 2003.

[14]Psaila B, Petrovic A, Page LK, et al. Intracranial hemorrhage (ICH) in children with immune thrombocytopenia (ITP): study of 40 cases. Blood ; 114:4777. 2009.

[15] Zeller B, Rajantie J, Hedlund-Treutiger I, et al.; Childhood idiopathic thrombocytopenic purpura in the Nordic 
countries: epidemiology and predictors of chronic disease. Acta Paediatr ; 94:178. 2005.

[16]Heitink-Pollé KM, Nijsten J, Boonacker $\mathrm{CW}$, et al. Clinical and laboratory predictors of chronic immune thrombocytopenia in children a systematic review and metaanalysis. Blood; 124:3295. 2014.

[17]Vesely S, Buchanan GR, Cohen A, et al.; Self-reported diagnostic and management strategies in childhood idiopathic thrombocytopenic purpura: results of a survey of practicing pediatric hematology/oncology specialists. J Pediatr Hematol Oncol; 22:55. (2000

[18]Tarantino MD ,Buchanan GR The pros and cons of drug therapy for immune thrombocytopenic purpura in children, Hematol Oncol Clin North Am. Dec, 18 (6): 1301-14 vii. .2004.

[19] Neunert C ,Lim W ,Crowther M, et al, The American society of Hematology : evidence -based practice guideline for immune thrombocytopenia ,Blood; Apr 21,117(16): 4190-207. 2011.

[20] Donato H, Picón A, Martinez M, et al.; Demographic data, natural history, and prognostic factors of idiopathic thrombocytopenic purpura in children: a multicentered study from Argentina. Pediatr Blood Cancer; 52:491. 2009.

[21]Imbach P, Kühne T, Müller D, et al.; Childhood ITP: 12 months follow-up data from the prospective registry $I$ of the Intercontinental Childhood ITP Study Group (ICIS). Pediatr Blood Cancer ; 46:351. 2006.
[22] Kühne T, Imbach P, Bolton-Maggs PH, et al.; Newly diagnosed idiopathic thrombocytopenic purpura in childhood: an observational study. Lancet; 358:2122. 2001. [23]Heitink-Polle KM, Uiterwaal CS, Pocelijn L, et al Treatment with Intravenous Immunoglobulin Does Not Prevent Chronic Immune Thrombocytopenia in Children: Results of a Randomized Controlled Trial. Blood; 866. 2016.

[24]Rosthøj S, Hedlund-Treutiger I, Rajantie $\mathrm{J}$, et al.; Duration and morbidity of newly diagnosed idiopathic thrombocytopenic purpura in children: A prospective Nordic study of an unselected cohort. J Pediatr; 143:302. 2003.

[25]John A. D’Orazio, Jessica Neely, et al ITP in Children :Pathophysiology and Current Treatment Approach ; Pediatr Hematol Oncol;35:1-13). 2013.

[26]Provan D, Stasi R, Newland AC, et al ; International consensus report on the investigation and management of primary immune thrombocytopenia Blood.;115(2):168.2010.

[27]British Committee for Standards in Hematology General Hematology Task Force Guidelines for the investigation and management of idiopathic thrombocytopenic purpura in adults, children and in pregnancy: Br J Haematol.; 120(4):574.2003.

[28]Kurtzberg J, Stockman JA 3rd.; Idiopathic autoimmune thrombocytopenic purpura. Adv Pediatr; 41:111.1994.

[29]Faki Osman ME: Childhood immune thrombocytopenia: Clinical presentation and 
management ;Sudan J Paediatr.; 12(1):27-39.

2012.

[30]Blanchette V, Bolton-Maggs P: Childhood immune thrombocytopenic purpura: diagnosis and management; Hematol Oncol Clin North Am. Feb; 24(1):249-73. 2010. 